BMJ Paediatrics Open

\section{Advance care planning for adolescent patients with life-threatening neurological conditions: a survey of Japanese paediatric neurologists}

Nobuyuki Yotani, ${ }^{1,2}$ Yoshiyuki Kizawa, ${ }^{2}$ Haruo Shintaku ${ }^{3}$
To cite: Yotani N, Kizawa Y, Shintaku H. Advance care planning for adolescent patients with life-threatening neurological conditions: a survey of Japanese paediatric neurologists. BMJ Paediatrics Open 2017;1:e000102. doi:10.1136/ bmjpo-2017-000102

- Additional material is published online only. To view please visit the journal online (http://dx.doi.org/10.1136/ bmjpo-2017-000102).

Received 26 May 2017 Revised 11 August 2017 Accepted 5 September 2017

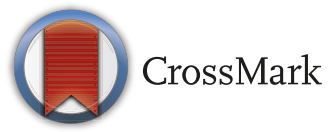

${ }^{1}$ Department of Palliative Medicine, National Centre for Child Health and Development, Tokyo, Japan

${ }^{2}$ Department of Palliative Medicine, Kobe University School of Medicine, Kobe, Japan ${ }^{3}$ Department of Pediatrics, Osaka City University Graduate School of Medicine, Osaka, Japan

Correspondence to Dr Nobuyuki Yotani, National Centre for Child Health and Development, 2-10-1 Okura Setagaya-ku, Tokyo 157-8535, Japan; yotani-n@ncchd.go.jp

\section{ABSTRACT}

Objective To evaluate current attitudes and barriers to advance care planning for adolescent patients with lifethreatening conditions among paediatric neurologists.

Design Cross-sectional study. A self-reported questionnaire was administered to assess the practice of advance care planning, advance directives and barriers to advance care planning for adolescent patients with life-threatening conditions. All board-certified paediatric neurologists in Japan were surveyed and those who had experience in taking care of adolescent patients with decision-making capacity were analysed. We compared the results with those of paediatric haematologists reported previously.

Results In total, 186 paediatric neurologists were analysed. If the patient's prognosis was $<3$ months, only about $30 \%$ of paediatric neurologists reported having discussions with patients, such as 'do not attempt resuscitation' orders $(28 \%)$ and ventilator use $(32 \%)$, whereas more than $70 \%$ did discuss these topics with patients' families. About half of the paediatric neurologists did not discuss advance directives at the end of life with their patients, whereas over $75 \%$ did discuss advance directives with patients' families. Compared with paediatric haematologists, paediatric neurologists had more end-oflife discussions with patients, such as where treatment and care will take place, do not attempt resuscitation orders, and the use of a ventilator, if the patient's prognosis was $>1$ year.

Conclusion About half or less of the paediatric neurologists discussed advance care planning and advance directives with their adolescent patients who had life-threatening conditions, even if the patient's prognosis was $<3$ months. They tended to discuss advance care planning and advance directives more with families than with patients themselves.

\section{INTRODUCTION}

Advance care planning (ACP) is, at its most basic, a process of thinking ahead to treatment choices, goals of care and/or choosing another person (proxy) to speak for oneself at a point in the future. ${ }^{1}$ Paediatric ACP is internationally recommended and welcomed by healthcare providers. ${ }^{23}$ It can increase the

\section{What is already known on this topic?}

Advance care planning for adolescent patients is gaining increasing attention.

- Neurological diseases are largely incurable and reduce life expectancy, so all neurologists should be knowledgeable about advance care planning, but it is a challenging area.

- There has been no research about the current practice of advance care planning or advance directives among paediatric neurologists caring for adolescent patients.

\section{What this study hopes to add?}

- About half or less of the paediatric neurologists discussed advance care planning with adolescent patients with life-threatening conditions, even if their prognosis was $<3$ months.

- They tended to discuss advance care planning and advance directives more with the families than with the patients themselves.

- Paediatric neurologists were more likely than paediatric haematologists to have discussion about advance directives like cardiopulmonary resuscitation and use of ventilator and vasopressor with patients.

capacity of children and parents to anticipate decisions, support family coping, provide peace of mind, increase sense of control and reduce suffering. ${ }^{4-6}$ One important result of an ACP discussion may be an advance directive $(\mathrm{AD})$, a written order delineating explicit wishes regarding medical interventions.

ACP with adolescent patients is gaining increasing attention, but is a difficult area of practice. Reports show that adolescent patients have the desire and ability to share their values, beliefs and preferences for treatment at the end of life. ${ }^{7-10}$ A previous study found that $75 \%$ of adolescent patients with cancer believed it was appropriate to discuss 
end-of-life decisions even before their condition worsened. ${ }^{11}$ However, some care providers exclude adolescent patients from ACP because they are deemed not legally competent to make decisions for themselves. ${ }^{5}$

While palliative care emerged with the treatment of patients with terminal cancer, more recent developments in this field suggest that palliative care may be appropriate for any neurological patient living with advanced, progressive illness or multiple comorbidities. ${ }^{12}$ Neurological diseases are largely incurable and reduce life expectancy, so all neurologists should be knowledgeable about, and feel comfortable discussing, ACP with patients and families. However, in the adult setting, many patients have never heard of ACP, and according to foreign report, $30 \%$ of patients with advance care plans do not share these with their physicians. ${ }^{13}$ There has been no research about the current $A C P$ and $A D$ practices among paediatric neurologists with regard to adolescent patients.

We reported previously that haematologists in Japan tended to discuss ACP and ADs more with the families than with the adolescent patients themselves. In fact, more than two-thirds of haematologists reported not having difficult discussions, such as do not attempt resuscitation (DNAR) orders, ventilator use, and prognosis, with their patients. ${ }^{14}$ To compare with haematologists, there is a possibility that it becomes clear whether the reason of the difficulty of ACP practice differs depending on the disease or depending on age.

The aim of the present study was to determine current practices regarding ACP and ADs among paediatric neurologists with regard to adolescent patients with life-threatening conditions. In addition, the study aimed to clarify differences between paediatric neurologists and paediatric haematologists in their attitudes and barriers to ACP and ADs for adolescent patients with life-threatening conditions.

\section{METHODS}

A self-reported questionnaire (see online supplementary file) was administered to paediatric neurologists to assess their practices regarding ACP and ADs, as well as barriers to ACP, for adolescent patients with life-threatening conditions.

\section{Study population}

All paediatric neurologists certified by the board of the Japanese Society of Child Neurology, the oldest and leading paediatric neurology academy in Japan, were surveyed. The total number of neurologists certified by the board was 1081. In order to compare the data of paediatric neurologists with those of paediatric haematologists, the data from paediatric haematologists regarding attitudes and barriers to ACP and ADs were extracted from a previously reported study that was conducted at the same time using the same questionnaire. ${ }^{14}$

\section{Data collection}

Mailing information for all board-certified paediatric neurologists was obtained from the Japanese Society of Child Neurology's web page. ${ }^{15}$ All eligible physicians were sent a letter explaining the study and containing a questionnaire, and requesting their participation. Paediatric neurologists for whom a mailing address was not available $(\mathrm{n}=37)$ were excluded from the study. A reminder letter was sent to all participants 4 months after the initial mail-out, except to those for whom the initial letters were returned because of incorrect addresses. Identifying information, such as names and addresses, was not linked to respondents' answers. Data were collected from October 2015 to May 2016 and were analysed for paediatric neurologists who indicated that they had experience in taking care of adolescent patients with life-threatening conditions who were also capable of making decisions like a kind of muscular dystrophy.

\section{Questionnaire}

The questionnaire consisted of 82 items. Items were adapted from existing surveys ${ }^{16} 17$ after minor revision, following discussions with specialists, namely three palliative care physicians, two paediatricians, two nurses and two psychotherapists. The survey was pilot-tested by a convenience sample of 15 physicians, including both paediatric neurologists and haematologists, and revised according to feedback from cognitive debriefing. All questions were close-ended, requiring categorical responses or rating on a Likert-type scale.

\section{Outcome measures}

\section{Practice of ACP}

The survey items concerning the individual physician's practices in relation to ACP were separated into two parts. The first part examined the physician's practice of ACP with adolescent patients with life-threatening conditions who had decision-making capacity and included questions regarding how frequently the physician did each of the following if their patient's prognosis was $>1$ year or $<3$ months:

- discuss the patient's medical condition

- verify the patient's understanding of his/her medical condition

- discuss the patient's prognosis

- discuss the goals of treatment and care

- promote sharing the treatment and care goals between the patient and his/her family

- discuss where treatment and care are to take place

- discuss 'do not attempt resuscitation' (DNAR) orders with the patient

- discuss ventilator treatment if the patient's condition worsens.

Physicians were required to answer these questions using a 5-point Likert-type scale: 'always', 'often', 'sometimes', 'rarely' or 'never'.

The second part of this section of the survey asked clinicians to answer the same questions, but with regard to discussions with the patients' families instead. 
Discussion about ADs at the end of life

Participants were asked about the discussions they have with patients with decision-making capacity about ADs at the end of life using the following binary question: 'Do you usually discuss resuscitation and life-prolonging therapy with patients with decision-making capacity if their prognosis is less than 4 weeks?' Participants were also asked about the discussions they have with patients with decision-making capacity regarding cardiopulmonary resuscitation and the use of ventilators, vasopressors, antibiotics, tube-feeding and intravenous fluids. The same questions were also used to investigate the participants' discussions of ADs with the patients' families.

\section{Barriers to ACP}

Using a 5-point Likert-type scale (always, often, sometimes, rarely or never), physicians were asked to rate how often 29 potential barriers were actual impediments to ACP. These questions were created on the basis of a previous study. ${ }^{17}$ Specific items assessed the physician's perception of barriers related to patient/family behaviours and practices, including patient/family expectations, readiness to have the discussion, understanding the medical issues and prognosis, and conflict between the patient and family members. Potential barriers related to physician behaviours/practices included concern about taking away hope or losing trust, not knowing the right things to say, the lack of a relationship with the patient and/or family, not knowing the right time to hold the discussion, uncertainty about the prognosis, physician expectations, lack of readiness to have the discussion, lack of time, physicians not placing much importance on ACP, lack of training, ethical considerations, and lack of laws and/or guidelines.

\section{Additional covariates}

\section{Sociodemographic characteristics}

Survey respondents were asked to report their specialty, their experience (years practising), age, sex and the number of dying patients under 18 years of age they have cared for over their entire career. In addition, they were asked to specify the type of medical facility in which they were currently working from the following choices: university hospital, children's hospital, other hospitals, rehabilitation centre, clinic or 'other'.

\section{Statistical analysis}

Statistical analyses were conducted using SAS V.9.2 (SAS Institute). Demographic data were summarised using descriptive statistics. Group comparisons between paediatric neurologists and haematologists were made using logistic regression model adjusted by sex, postgraduate experience and the number of dying patients under 18 years of age they have cared for over their entire career. In the present study, questions regarding ACP practices rated using Likert-type scales were dichotomised as follows: 0, 'sometimes', 'rarely' or 'never'; 1, 'always' or 'often'. Similarly, responses regarding barriers to ACP
Table 1 Characteristics of the study participants

All $(n=186)$

\begin{tabular}{lc}
\hline Age (year) & $53.4 \pm 10.6$ \\
\hline Postgraduate experience (year) & $28.3 \pm 10.7$ \\
\hline No. of men & $126(68)$ \\
\hline Place of work & $54(29)$ \\
\hline University hospital & $52(28)$ \\
\hline Other hospital & $44(24)$ \\
Rehabilitation centre & $17(9)$ \\
\hline Clinic & $12(7)$ \\
\hline Children's hospital & $5(3)$ \\
\hline Other & $2(1)$ \\
No. of dying patients <18years of age cared for \\
\hline 0 & $11(6)$ \\
$1-4$ & $39(21)$ \\
\hline $5-9$ & $65(35)$ \\
$10-19$ & $32(17)$ \\
\hline $20-29$ & $37(20)$ \\
\hline $30+$ & \\
\hline
\end{tabular}

Data are presented as the mean \pm SD or as $\mathrm{n}(\%)$.

were dichotomised as a barrier frequency variable as: 0, 'sometimes', 'rarely' or 'never'; 1, 'always' or 'often'. Although this system was used to dichotomise variables in the present study, there were no differences in results if we dichotomised variables as 'rarely or never' versus all other categories or 'never' alone versus all other categories.

\section{RESULTS}

Of the paediatric neurologists eligible to participate in the study, responses were obtained from 564 (response rate $54 \%$ ). Finally, data were analysed for 186 paediatric neurologists who indicated that they had experience in taking care of adolescent patients with life-threatening conditions and decision-making abilities.

\section{Sample characteristics}

The characteristics of the study participants are given in table 1. Average year of postgraduate experience (SD) was 28.3 (10.7) and $70 \%$ of paediatric neurologists had experience in caring for more than 10 dying patients $<18$ years of age (table 1 ).

\section{ACP practices of paediatric neurologists for adolescent patients with life-threatening conditions}

The ACP practices of paediatric neurologists for adolescent patients with life-threatening conditions are summarised in table 2 and compared with paediatric haematologists. If the patient's prognosis was $>1$ year, fewer than $50 \%$ of neurologists discussed with the patient his/her medical condition $(48 \%)$, verified the patient's understanding of his/her medical condition $(43 \%)$, or 
Table 2 ACP practices of paediatric neurologists compared with paediatric haematologists

\section{Number of paediatricians who answered 'often' or 'always' for each question \\ Neurologists Haematologists \\ $(n=186) \quad(n=227)$ \\ p Value}

\begin{tabular}{|c|c|c|c|}
\hline \multicolumn{4}{|l|}{ Adolescent patients } \\
\hline \multicolumn{4}{|l|}{ Prognosis $>1$ year } \\
\hline Discuss medical condition & $85(48)$ & $155(69)$ & $<0.01$ \\
\hline Verify understanding of medical condition & $77(43)$ & $136(61)$ & 0.01 \\
\hline Promote sharing of treatment and care goals between patients and families & $28(16)$ & $135(61)$ & 0.43 \\
\hline Discuss goals of treatment and care & $88(49)$ & $126(57)$ & 0.22 \\
\hline Discuss where treatment and care will take place & $88(50)$ & $98(44)$ & 0.13 \\
\hline Discuss prognosis & $64(36)$ & $52(23)$ & 0.37 \\
\hline Discuss DNAR & $19(11)$ & $17(8)$ & 0.18 \\
\hline Discuss ventilator treatment if the patient's condition worsens & $35(20)$ & $17(8)$ & $<0.01$ \\
\hline \multicolumn{4}{|l|}{ Prognosis $<3$ months } \\
\hline Discuss medical condition & $100(56)$ & $135(59)$ & 0.57 \\
\hline Verify understanding of medical condition & $97(55)$ & $125(55)$ & 0.56 \\
\hline Promote sharing of treatment and care goals between patients and families & $65(37)$ & $133(59)$ & 0.04 \\
\hline Discuss goals of treatment and care & $91(51)$ & $125(55)$ & 0.93 \\
\hline Discuss where treatment and care will take place & $100(57)$ & $111(50)$ & 0.65 \\
\hline Discuss prognosis & $84(49)$ & $67(30)$ & 0.64 \\
\hline Discuss DNAR & $49(28)$ & $38(17)$ & $<0.01$ \\
\hline Discuss ventilator treatment if the patient's condition worsens & $56(32)$ & $42(19)$ & $<0.01$ \\
\hline \multicolumn{4}{|l|}{ Family } \\
\hline \multicolumn{4}{|l|}{ Prognosis $>1$ year } \\
\hline Discuss medical condition & $151(83)$ & $201(92)$ & 0.05 \\
\hline Verify understanding of medical condition & $151(83)$ & $200(91)$ & 0.04 \\
\hline Promote sharing of treatment and care goals between patients and families & $143(79)$ & $192(88)$ & 0.58 \\
\hline Discuss goals of treatment and care & $144(80)$ & $188(86)$ & 0.13 \\
\hline Discuss where treatment and care will take place & $135(75)$ & $181(83)$ & 0.11 \\
\hline Discuss prognosis & $118(67)$ & $163(75)$ & 0.29 \\
\hline Discuss DNAR & $84(46)$ & $96(44)$ & 0.78 \\
\hline Discuss ventilator treatment if the patient's condition worsens & $94(52)$ & $95(43)$ & 0.18 \\
\hline \multicolumn{4}{|l|}{ Prognosis $<3$ months } \\
\hline Discuss medical condition & $158(89)$ & $213(96)$ & 0.03 \\
\hline Verify understanding of medical condition & $157(88)$ & $212(96)$ & 0.10 \\
\hline Promote sharing of treatment and care goals between patients and families & $156(88)$ & $207(94)$ & 0.23 \\
\hline Discuss goals of treatment and care & $153(86)$ & $207(94)$ & 0.18 \\
\hline Discuss where treatment and care will take place & $152(85)$ & $202(91)$ & 0.30 \\
\hline Discuss prognosis & $146(82)$ & $196(89)$ & 0.23 \\
\hline Discuss DNAR & $124(70)$ & $162(73)$ & 0.68 \\
\hline Discuss ventilator treatment if the patient's condition worsens & $136(76)$ & $166(75)$ & 0.30 \\
\hline
\end{tabular}

Data are presented as $\mathrm{n}(\%)$. Percentage was calculated based on the number of respondents for each item.

$\mathrm{p}$ Values were calculated by logistic regression adjusted for sex, postgraduate experience and number of dying patients $<18$ years of age cared for.

ACP, advance care planning; DNAR, do not attempt resuscitation. 


\begin{tabular}{|c|c|c|c|}
\hline & Numbe & ns who held discl & \\
\hline & $\begin{array}{l}\text { Neurologists } \\
(n=186)\end{array}$ & $\begin{array}{l}\text { Haematologists } \\
(n=227)\end{array}$ & p Value \\
\hline Adolescent patients & & & \\
\hline Cardiopulmonary resuscitation & & & \\
\hline Use of: & & & \\
\hline Ventilator & $99(57)$ & $70(31)$ & $<0.01$ \\
\hline Vasopressor & $73(42)$ & $54(24)$ & $<0.01$ \\
\hline Antibiotics & $62(36)$ & $47(21)$ & $<0.01$ \\
\hline Tube-feeding & $88(51)$ & $90(40)$ & $<0.01$ \\
\hline Intravenous fluids & $74(43)$ & $74(33)$ & 0.03 \\
\hline Family & & & \\
\hline Cardiopulmonary resuscitation & $162(93)$ & $215(99)$ & 0.10 \\
\hline Use of: & & & \\
\hline Ventilator & $170(97)$ & $213(98)$ & 0.60 \\
\hline Vasopressor & $156(89)$ & $192(88)$ & 0.34 \\
\hline Antibiotics & $131(76)$ & $115(53)$ & $<0.01$ \\
\hline Tube-feeding & $145(83)$ & $160(74)$ & 0.10 \\
\hline Intravenous fluids & $131(75)$ & $140(65)$ & 0.04 \\
\hline
\end{tabular}

Data are presented as $\mathrm{n}(\%)$. Percentage was calculated based on the number of respondents for each item.

$p$ Values were calculated by logistic regression adjusted for sex, postgraduate experience and number of dying patients $<18$ years of age cared for.

$A D$, advance directives.

promoted the sharing of the treatment and care goals between patient and family (16\%). If the patient's prognosis was $<3$ months, $49 \%$ of neurologists discussed prognosis with the patient and about $30 \%$ discussed DNAR orders $(28 \%)$ and the use of a ventilator if the patient's condition worsened $(32 \%)$. On the other hand, more than $70 \%$ of paediatric neurologists discussed all the ACP topics with the patient's family if the patient's prognosis was $<3$ months. If the patient's prognosis was $>1$ year, paediatric neurologists were significantly less likely to discuss with the patient his/her medical condition or verify the patient's understanding of his/her medical condition compared with paediatric haematologists. Conversely, paediatric neurologists were more likely than paediatric haematologists to have end-of-life discussions with the patient, such as where treatment and care will take place, DNAR orders and the use of a ventilator if their condition worsened (table 2).

\section{Discussion about ADs at the end of life}

Discussions between physicians and patients and their families regarding ADs at the end of life are summarised in table 3. More than half of the neurologists discussed the use of ventilators $(57 \%)$ and tube-feeding (51\%) with their patients. In addition, paediatric neurologists discussed all the $\mathrm{AD}$ topics more often with the patients' families than with the patients themselves. Overall, neurologists were significantly more likely than haematologists to discuss all the $\mathrm{AD}$ topics with their patients (table 3).

\section{Barriers to ACP}

Table 4 lists the factors that physicians identified as often or always acting as barriers to ACP. More than $50 \%$ of neurologists reported that unrealistic family expectations $(58 \%)$, differences in the understanding of the prognosis between the physician and family $(54 \%)$, differences in the understanding of the prognosis between the physician and patient (53\%), lack of training (53\%) and insufficient laws and guidelines $(50 \%)$ were barriers to ACP. In general, neurologists perceived more barriers than haematologists. There were significant differences between neurologists and haematologists regarding eight barriers to ACP, namely insufficient laws and guidelines, inability of family/patient to fully comprehend the issue, uncertainty about the prognosis, lack of physician time, lack of a relationship between the physician and the family/patient, and physicians not placing much importance on ACP (table 4).

\section{DISCUSSION}

To the best of our knowledge, the present study is the first study to investigate current $\mathrm{ACP}$ and $\mathrm{AD}$ practices among 
Table 4 Barriers to ACP

\begin{tabular}{ll}
$\begin{array}{c}\text { Number of paediatricians who answered } \\
\text { 'often' or 'always' for each question }\end{array}$ \\
\hline $\begin{array}{l}\text { Neurologists } \\
(n=186)\end{array}$ & $\begin{array}{l}\text { Haematologists } \\
(n=227)\end{array}$
\end{tabular}

p Value

Unrealistic family expectations

Differences in understanding the prognosis

\begin{tabular}{|c|c|c|c|}
\hline Between physician and family & $94(54)$ & $94(42)$ & 0.07 \\
\hline Between physician and patient & $93(53)$ & $103(46)$ & 0.37 \\
\hline Lack of training & $93(53)$ & $112(51)$ & 0.91 \\
\hline Insufficient laws and guidelines & $88(50)$ & $74(33)$ & 0.02 \\
\hline Physician concerned about taking away patient's hope & $85(49)$ & $94(43)$ & 0.75 \\
\hline Family not ready to have the discussion & $86(49)$ & $86(39)$ & 0.97 \\
\hline Unrealistic patient expectations & $87(49)$ & $80(36)$ & 0.28 \\
\hline Ethical considerations & $85(49)$ & $85(38)$ & 0.24 \\
\hline Family unable to fully comprehend the issue & $87(49)$ & $69(32)$ & $<0.01$ \\
\hline $\begin{array}{l}\text { Differences in understanding the prognosis between patients and } \\
\text { family }\end{array}$ & $82(47)$ & $87(39)$ & 0.17 \\
\hline Patient unable to fully comprehend the issue & $82(47)$ & $68(31)$ & 0.03 \\
\hline Patient not ready to have the discussion & $83(47)$ & $93(42)$ & 0.79 \\
\hline Physician does not know the right time to address the issue & $76(43)$ & $96(43)$ & 0.33 \\
\hline Physician concerned about taking away family's hope & $67(38)$ & $67(31)$ & 0.70 \\
\hline Physician uncertain about the prognosis & $63(36)$ & $58(26)$ & 0.04 \\
\hline Physician does not know the things to say & $60(34)$ & $59(27)$ & 0.68 \\
\hline Conflict between parents and other family members & $58(33)$ & $58(27)$ & 0.95 \\
\hline Physician not ready to have the discussion & $56(32)$ & $59(27)$ & 0.92 \\
\hline Conflict between patient and parents & $52(30)$ & $54(25)$ & 0.79 \\
\hline Lack of physician time & $49(28)$ & $40(18)$ & 0.04 \\
\hline No relationship between physician and family & $47(27)$ & $24(11)$ & $<0.01$ \\
\hline No relationship between physician and patient & $42(24)$ & $23(11)$ & $<0.01$ \\
\hline Physician concerned about losing the trust of the patient & $34(19)$ & $33(15)$ & 0.460 .29 \\
\hline Physician concerned about losing the trust of the family & $33(19)$ & $30(14)$ & 0.57 \\
\hline Physician considers ACP not that important & $27(17)$ & $17(8)$ & 0.01 \\
\hline Unrealistic physician expectations & $27(15)$ & $20(9)$ & 0.49 \\
\hline $\begin{array}{l}\text { Physician concerned that the family will receive less attention from } \\
\text { physicians }\end{array}$ & $27(15)$ & $23(10)$ & 0.40 \\
\hline $\begin{array}{l}\text { Physician concerned that the patient will receive less attention from } \\
\text { physicians }\end{array}$ & $23(13)$ & $22(10)$ & 0.45 \\
\hline
\end{tabular}

Data are presented as $\mathrm{n}(\%)$. Percentage was calculated based on the number of respondents for each item.

$p$ Values were calculated by logistic regression adjusted for sex, postgraduate experience and number of dying patients $<18$ years of age cared for.

ACP, advance care planning.

paediatric neurologists with regard to adolescent patients with life-threatening conditions.

The most important finding of the present study was that only about half or less of the paediatric neurologists discussed ACP and ADs with their adolescent patients who had life-threatening conditions, even if the patient's prognosis was $<3$ months. They tended to discuss ACP and ADs more with the families than with their patients.
In fact, if the patient's prognosis was $<3$ months, only about $30 \%$ of paediatric neurologists reported having discussions, such as DNAR orders and ventilator use, with their patients, whereas over $70 \%$ did discuss these topics with the patients' families. About half of the paediatric neurologists did not discuss ADs at the end of life with their patients, whereas over $75 \%$ did discuss ADs with the patients' families. We reported previously 
that haematologists, both paediatricians and internists, tended to discuss ACP and ADs more with the families than with the adolescent patients themselves. ${ }^{14}$ These findings show that discussions about ACP and ADs with adolescent patients with life-threatening conditions are less frequent with all physicians, regardless of the type of clinical practice.

The second important finding of the present study was that paediatric neurologists were more likely than haematologists to have end-of-life discussions, such as prognosis and ADs with patients. In fact, if the patient's prognosis was $<3$ months, about $50 \%$ of paediatric neurologists reported they discussed prognosis with their adolescent patients, whereas only $30 \%$ of haematologists discussed it. A possible explanation for this is due to the difference in illness trajectories between neurological diseases and haematological malignancies. Patients with life-threatening neurological illnesses are more likely to experience sudden and critical changes in their disease condition due to respiratory failure, cognitive impairment and motor paralysis in the course of illness. Therefore, neurologists may be more accustomed to having end-of-life discussions than haematologists. Conversely, neurologists were less likely than haematologists to have more basic end-of-life discussions with patients, such as current medical condition and treatment and care goals. In contrast to cancer, neurological illnesses have a longer and more variable time course, and it is often hard to determine exactly when a patient is entering the terminal stages of life. ${ }^{18}$ Therefore, neurologists may feel less familiar having basic discussions with patients than haematologists.

The third important finding of the present study was the identification of barriers to ACP from the perspective of paediatric neurologists who had experience in taking care of adolescents with life-threatening conditions who had decision-making capacity. The ranking of barriers to ACP was almost the same between paediatric neurologists and haematologists, but paediatric neurologists felt more barriers to ACP than haematologists. Family factors were one of the most common barriers for paediatric neurologists as well as haematologists. In addition, patient factors were also identified as barriers to ACP. Neurologists felt more barriers than haematologists about patients being unable to comprehend the issues. This may reflect the fact that patients with neurological illness often have decreasing cognitive impairment during the course of disease progression. Similar to haematologists, a lack of training and the concern of taking away hope from patients were physician factors that acted as major barriers to ACP for neurologists. Providing opportunities for training about end-of-life communication may reduce barriers to ACP and improve for practice of ACP discussion.

The present study had several limitations. First, the response rate was not high. The motivation for either agreeing or refusing to participate in the study may be biased by previous experiences of the study topics, so a higher response rate is likely to make the proportion of neurologists reporting ACP and $\mathrm{AD}$ discussions smaller. Second, there would be the potential for recall bias. Third, the generalisation of the findings of the present study may be limited because the ACP process may be affected by cultural differences.

\section{CONCLUSION}

The findings of the present study indicate that about half or less of paediatric neurologists discussed ACP and ADs with their adolescent patients with life-threatening conditions, even if the patient's prognosis was $<3$ months. They tended to discuss ACP and ADs more with families than with the patients themselves. Compared with paediatric haematologists, paediatric neurologists were more likely to have end-of-life discussions with their patients.

Contributors NY conducted the research (including leading the literature review, collecting, analysing and interpreting data), led the drafting of this paper, contributed to critical revisions and shares accountability for this manuscript. YK acted as second supervisor on the research, helped design the project, aided in the interpretation and analysis of data, critically revised this paper and approved and shares accountability for this manuscript. HS acted as first supervisor on the research, helped design the project, aided in the interpretation and analysis of data, critically revised this paper and approved and shares accountability for this manuscript

Funding This study was funded by the Ministry of Education, Culture, Sports, Science and Technology.

Competing interests None declared.

Ethics approval The Institutional Review Board of Osaka City University Medical School (Approval No. 3126).

Provenance and peer review Not commissioned; externally peer reviewed.

Open Access This is an Open Access article distributed in accordance with the Creative Commons Attribution Non Commercial (CC BY-NC 4.0) license, which permits others to distribute, remix, adapt, build upon this work non-commercially, and license their derivative works on different terms, provided the original work is properly cited and the use is non-commercial. See: http://creativecommons.org/ licenses/by-nc/4.0/

(C) Article author(s) (or their employer(s) unless otherwise stated in the text of the article) 2017. All rights reserved. No commercial use is permitted unless otherwise expressly granted.

\section{REFERENCES}

1. Romer AL, Hammes BJ. Communication, trust, and making choices: advance care planning four years on. J Palliat Med 2004;7:335-40.

2. Tsai E. Advance care planning for paediatric patients. Paediatr Child Health 2008;13:791-6.

3. Lotz JD, Jox RJ, Borasio GD, et al. Pediatric advance care planning from the perspective of health care professionals: a qualitative interview study. Palliat Med 2015;29:212-22.

4. Lotz JD, Jox RJ, Borasio GD, et al. Pediatric advance care planning: a systematic review. Pediatrics 2013;131:e873-e880.

5. Hammes BJ, Klevan J, Kempf M, et al. Pediatric advance care planning. J Palliat Med 2005;8:766-73.

6. Lyon ME, Jacobs S, Briggs L, et al. A longitudinal, randomized, controlled trial of advance care planning for teens with cancer: anxiety, depression, quality of life, advance directives, spirituality. $J$ Adolesc Health 2014;54:710-7.

7. Wiener L, Ballard E, Brennan T, et al. How I wish to be remembered: the use of an advance care planning document in adolescent and young adult populations. J Palliat Med 2008;11:1309-13.

8. Lyon ME, McCabe MA, Patel KM, et al. What do adolescents want? An exploratory study regarding end-of-life decision-making. $J$ Adolesc Health 2004;35:529.e1-529.e6. 
9. Lyon ME, Garvie PA, McCarter R, et al. Who will speak for me? Improving end-of-life decision-making for adolescents with HIV and their families. Pediatrics 2009;123:e199-e206.

10. Hinds PS, Drew D, Oakes LL, et al. End-of-life care preferences of pediatric patients with cancer. J Clin Oncol 2005; 23:9146-54.

11. Jacobs S, Perez J, Cheng YI, et al. Adolescent end of life preferences and congruence with their parents' preferences: results of a survey of adolescents with cancer. Pediatr Blood Cancer 2015;62:710-4.

12. Boersma I, Miyasaki J, Kutner J, et al. Palliative care and neurology: time for a paradigm shift. Neurology 2014; 83:561-7.

13. Heyland DK, Barwich D, Pichora D, et al. Failure to engage hospitalized elderly patients and their families in advance care planning. JAMA Intern Med 2013;173:778-87.
14. Yotani N, Kizawa Y, Shintaku H. Difference between pediatricians and internists in advance care planning for adolescents with cancer. J Pediatr 2017;182:356-62.

15. Japanese Society of Child Neurology, Board certified member of the Japanese Society of Child Neurology. Pediatric neurologist rosters. https://www.childneuro.jp/modules/about/index.php?content_id=10 (accessed 15 Feb 2017).

16. Nakazawa K, Kizawa Y, Maeno T, et al. Palliative care physicians' practices and attitudes regarding advance care planning in palliative care units in Japan: a nationwide survey. Am J Hosp Palliat Care 2014;31:699-709.

17. Durall A, Zurakowski D, Wolfe J. Barriers to conducting advance care discussions for children with life-threatening conditions. Pediatrics 2012;129:e975-e982.

18. Murray SA, Sheikh A. Palliative care beyond cancer: care for all at the end of life. BMJ 2008;336:958-9. 